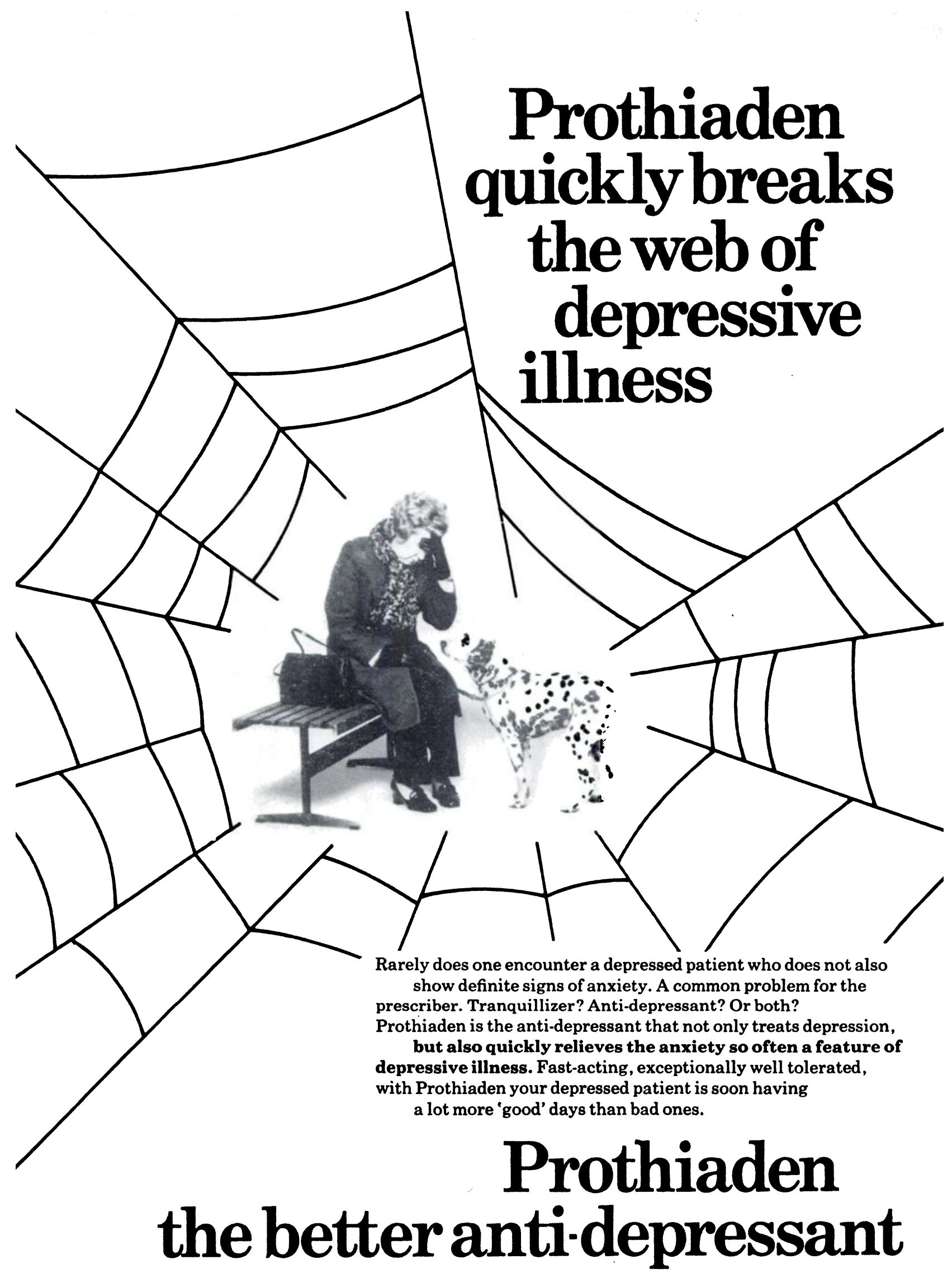

Tablets containing dothiepin hydrochloride $25 \mathrm{mg}$. Full information on request from The Crookes Laboratories Ltd., Basingstoke, Hants. 


\section{When your}

schizophrenic patient

needs a depot antipsychotic injection that

* is alerting ${ }_{0.2 \mathrm{v}}$

* has antidepressant activity

* is effective for 3 weeks on average ${ }_{\text {a.o }}$

* has a low incidence of extrapyramidal side effects

\section{prescribe \\ DEPIXOL INJECTION}

(flupenthixol decanoate)

Roterences:

1. British Journal of Psychiatry. (1973) 122, 371.

2. British Journal of Psychiatry. (1972) 120, 241.

3. British Journal of Psychiatry. (1973) In Press.

4. British Journal of Psychiatry. (1973) 122, 120.

5. British Journal of Psychiatry. (1971) 119, 230.

6. British Journal of Psychiatry. (1972) 121, 458.

LUNDBECK LIMITED

The Green, Welwyn, Herts.

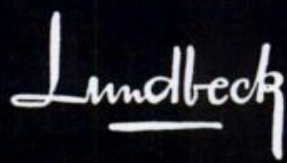

Holders of product licence no. $0458 / 0007$ Made in Denmark by H. Lundbeck $\&$ Co. A/S 